\title{
Influence of the Nature of Porphyrin and Extraligand on the Stability of Zinc Extracomplexes
}

\author{
Svetlana V. Zaitzeva*, Sergey A. Zdanovich, Tatiana A. Ageeva, Alexandr S. Ocheretovi and \\ Oleg A. Golubchikov \\ Institute of the Solution Chemistry of Russian Academy of Sciences, Akademicheskaya, 1, 153045, \\ Ivanovo, Russian Federation
}

Tel.: +7 0932 378512, E-mail: svz@ihnr.polytech.ivanovo.su

Received: 15 March 2000 / Accepted: 29 April 2000 / Published: 9 June 2000

\begin{abstract}
The mutual influence of ligands within the structure of $\mathrm{Zn}$-porphyrins on the thermodynamic stability of the latter was investigated.
\end{abstract}

Keywords: Extracoordination, complex, metalloporphyrins, stability.

\section{Introduction}

The influence of the nature of porphyrin and extraligand on the process of formation of extracomplexes of zinc porphyrins in $o$-xylene was studied by a spectrophotometrical titration method and computer simulation. For the research the following metalloporphyrins were used: zinc 5,15-(parabutyloxyphenyl)-2,8,12,18-tetramethyl-3,7,13,17-tetraethylporphyrin $\mathbf{Z n P ( I ) , ~ z i n c ~ 5 , 1 5 - ( p a r a - b u t y l - ~}$ oxyphenyl)-2,8,12,18-tetramethyl-3,7,13,17-tetrabutylporhyrin ZnP(II), superimposed zinc porphyrin ZnP(III) and zinc tetraphenylporphyrin ZnP(IV). N-methylimidazole (MeIm), imidazole (Im), pyridine (Py), 3,5-dimethylpyrazole (DMP) and dimethylformamide (DMF) were used as extraligands (L). The strength of Zn-L bonding was noted to be lower within the series of extracomplex stuctures: $\mathbf{Z n P ( I V ) ~ > ~}$ $\mathbf{Z n P}(\mathbf{I})>\mathbf{Z n P}($ II) $)>\mathbf{Z n P}\left(\right.$ III). The stability constant $\left(\lg K_{\mathrm{S}}\right)$ in the case of sterically unhindered complexes was found to increase linearly with the increase of basisity of the extraligand $\left(\lg K_{\mathrm{BH}^{+}}\right)$. For sterically hindered $\mathbf{Z n P ( I ) , ~} \mathbf{Z n P}\left(\right.$ II) and $\mathbf{Z n P}\left(\right.$ III) the values of $\lg K_{\mathrm{S}}$ and $\lg K_{\mathrm{BH}}+$ and also $\lg K_{\mathrm{S}}$ and $\Delta \lambda$ var-

(C) 2000 by MDPI (http://www.mdpi.org). Reproduction is permitted for noncommercial purposes. 
ied non-linearly. Geometrical structures was computed by quantum - chemical methods and the energy characteristics of pentacoordinated zincporphyrin complexes were obtained. Correlations were found between calculated values of the interaction energy of the central metal atom with extraligand molecules and the stability of Zn-porphyrin extracomplexes.

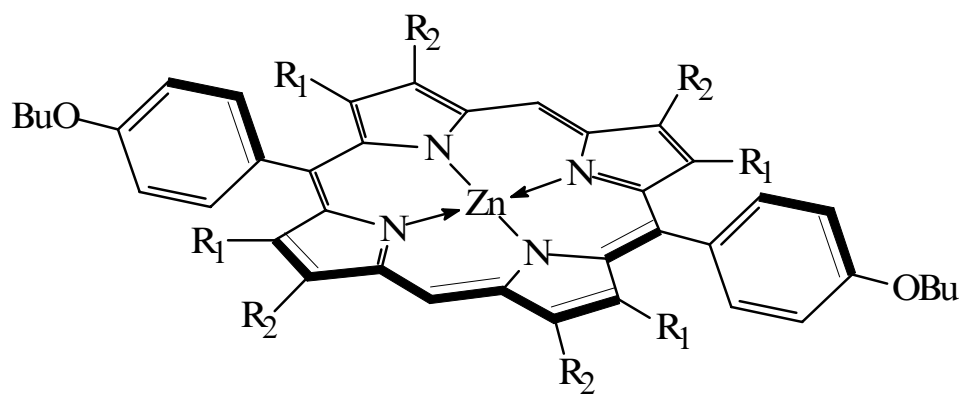

ZnP(I) $\mathrm{R}_{1}=\mathrm{Et}, \mathrm{R}_{2}=\mathrm{Me} ; \mathbf{Z n P}(\mathrm{II}) \mathrm{R}_{1}=\mathrm{Bu}, \mathrm{R}_{2}=\mathrm{Me}$

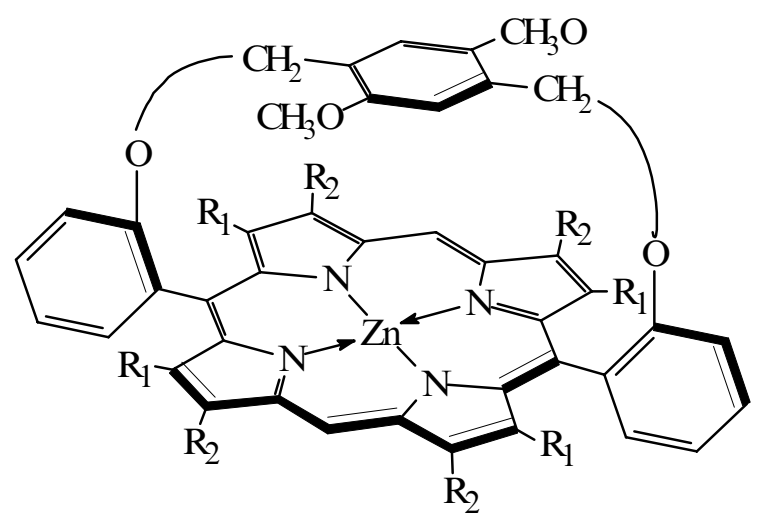

ZnP(III) $\mathrm{R}_{1}=\mathrm{Me}, \mathrm{R}_{2}=\mathrm{Bu}$

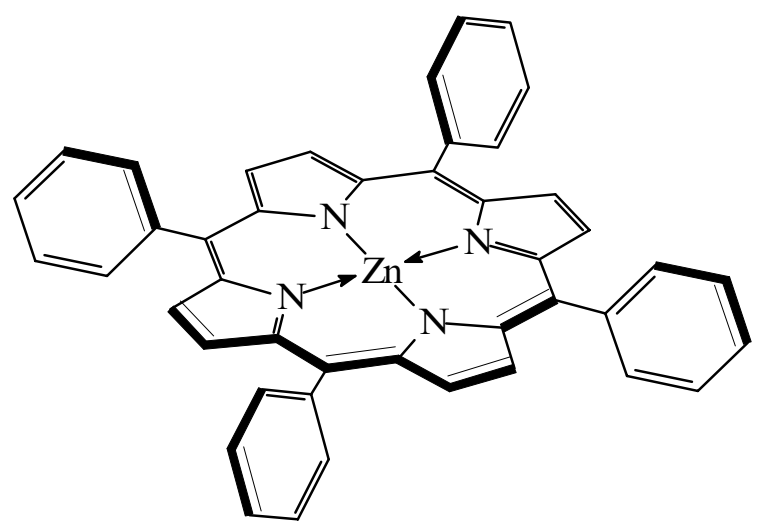

ZnP(IV)

Figure 1. 


\section{Results and Discussion}

The binding of ligands L with Zn-porphyrins in all cases is accompanied by bathocromic shifts and with changes of intensity of the chromophore basic absorption bands (Figure 2). It is our point of view that this is due to the increase of electron density at the zinc cation and at the porphyrin nitrogen atoms. The growth of a fractional negative charge at $\mathrm{N}$ atoms establishes the destabilisation of the $a_{2 u}$ molecular orbital at $a_{1} u$. constant level. As a result the configuration interaction of the $E_{u}$-type excited state decreases, and that is sufficient reason for amplification of the first band in the electronic absorption spectra (EAS) of Zn-porphyrins. The bathochromic shift, probably, is caused by the increase in energy of the $a_{2 u}$ - type MO.
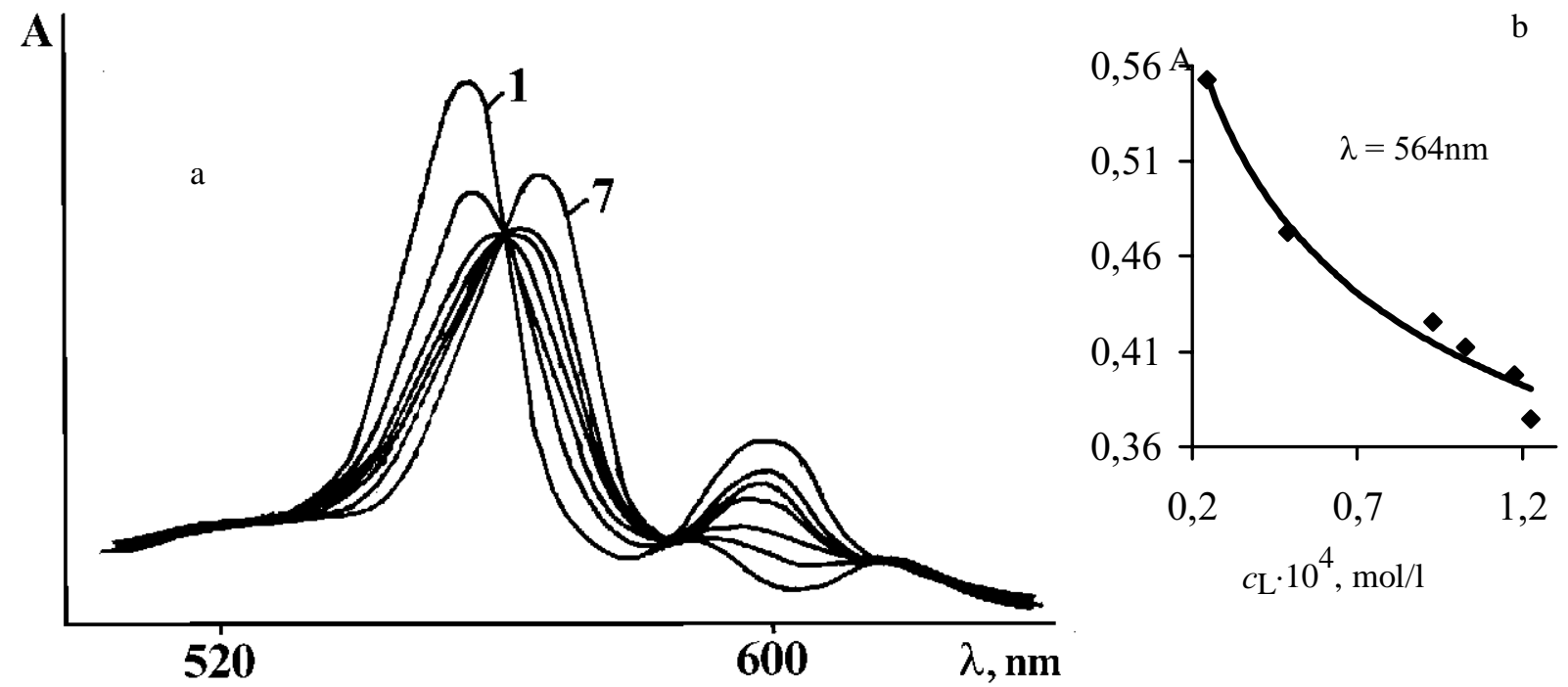

Figure 2. EAS of $\mathrm{ZnP}(\mathrm{IV})$ with imidazole in $o$-xylene; $1-7$ - $\mathrm{ZnP}(\mathrm{IV})$ with concentration $\operatorname{Im} 0 \div 0,1$ • $10^{-3} \mathrm{~mol} / \mathrm{l}$ (a) and corresponding titration curve (b).

During the study complexes $\mathbf{Z n P ( I ) , ~} \mathbf{Z n P}($ II), $\mathbf{Z n P ( I I I )}$ were found to have the property of attaching one molecule of MeIm, Im, DMP, Py, DMF. For ZnP(IV) the coordination of two molecules of extraligand is observed only in the case of DMF. $K_{\mathrm{S}}$ values obtained, calculated characteristics of geometric structure and energy parameters of molecules of Zn-porphyrins are presented in Tables 1 and 2. The comparison of the data in Table 1 enables us to estimate the strength of additional ligand binding with $\mathrm{Zn}$-porphyrins and to establish a series for their stability. In the case of formation of extracomplexes of Zn-porphyrins with MeIm and Im the series is: $\mathbf{Z n P ( I V )}>\mathbf{Z n P}(\mathbf{I I}) \approx \mathbf{Z n P}(\mathbf{I})>\mathbf{Z n P}($ III $)$. This is explained by the influence of porphyrin ligand nature on the extracoordination process. In the case of $\mathbf{Z n P ( I V ) , ~ t h e ~ e l e c t r o n ~ d e n s i t y ~ w i t h d r a w a l ~ f r o m ~ t h e ~ z i n c ~ a t o m ~ b y ~ p h e n y l ~ r i n g s ~ i n c r e a s e s ~ i t s ~ p a r t i a l ~ p o s i - ~}$ tive charge. Hence, the Zn-L bonding becomes stronger. The decrease of the number of phenyl substi- 


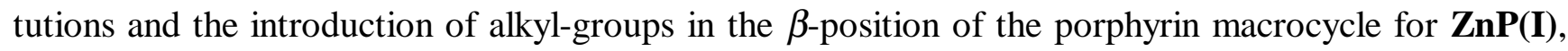
$\mathbf{Z n P}(\mathbf{I I})$, leads to an increase of electron densities at nitrogen atoms in the coordination center and to the decrease of positive charge at the zinc atom that reduces the strength of $\mathrm{Zn}-\mathrm{L}$ bonding. Thus, extracomplexes (L)ZnP(I), (L)Zn(II) are less stable in comparison with (L)ZnP(IV). The low value of the stability constant of extracomplexes (L)ZnP(III) in comparison with the remaining members of the series is explained not only by the influence of substituents on the porphyrin macrocycle, but by its distortion as a result of steric strain caused by the "cover".

Stability constants of zinc complexes with Py are practically the same (Table 1) and the nature of porphyrin ligand, in this case, has practically no influence on the process of extracoordination. The reason of such anomalous behavior of pyridine remains unexplainable.

Table 1. Thermodynamic characteristics of extracoordination reactions of nitrogen-containing ligands by zinc complexes of porphyrins in $o$-xylene.

\begin{tabular}{|c|c|c|c|c|}
\hline Complex & Extraligand & $\begin{array}{c}K_{\mathrm{S}}^{298} \cdot 10^{-3} \\
\operatorname{mol}^{-1} \cdot 1\end{array}$ & $\begin{array}{l}E_{\mathrm{b}} \mathrm{Zn}-\mathrm{L} \\
\mathrm{kcal} / \mathrm{mol}\end{array}$ & $\Delta \lambda, \mathrm{nm}$ \\
\hline \multirow[t]{5}{*}{$\mathrm{ZnP}(\mathrm{I})$} & Me-Im & $0.477 \pm 0.001$ & -16.01 & 5.0 \\
\hline & $\mathrm{Im}$ & $4.4 \pm 0.1$ & -15.94 & 12.0 \\
\hline & $\mathrm{Py}$ & $1.14 \pm 0.06$ & -4.52 & 9.0 \\
\hline & DMP & $1.64 \pm 0.03$ & -12.85 & 10.0 \\
\hline & DMF & $0.019 \pm 0.001$ & 0.05 & 2.5 \\
\hline \multirow[t]{5}{*}{ ZnP(II) } & Me-Im & $0.56 \pm 0.01$ & - & 5.0 \\
\hline & $\operatorname{Im}$ & $6.7 \pm 0.4$ & - & 17.0 \\
\hline & Py & $1.8 \pm 0.1$ & - & 10.0 \\
\hline & DMP & $1.9 \pm 0.1$ & - & 10.5 \\
\hline & DMF & $0.15 \pm 0.02$ & - & 4.0 \\
\hline \multirow[t]{4}{*}{ ZnP(III) } & Me-Im & $0.46 \pm 0.02$ & -0.0299 & 4.0 \\
\hline & $\operatorname{Im}$ & $0.93 \pm 0.01$ & -0.0298 & 8.0 \\
\hline & Py & $0.24 \pm 0.02$ & -0.0256 & 3.0 \\
\hline & DMF & $0.042 \pm 0.003$ & -0.0097 & 2.0 \\
\hline \multirow[t]{5}{*}{ ZnP(IV) } & Me-Im & $110 \pm 8$ & -290.21 & 15.5 \\
\hline & $\mathrm{Im}$ & $15 \pm 2$ & -152.77 & 14.5 \\
\hline & Py & $1.8 \pm 0.1$ & -147.73 & 11.0 \\
\hline & DMP & $1.5 \pm 0.2$ & $-145 . .36$ & 10.0 \\
\hline & DMF & $0.6 \pm 0.01$ & 1.90 & 15.0 \\
\hline
\end{tabular}

The nature of the extraligand has an effect on the stability of Zn-porphyrin extracomplexes. The 
strength of $\mathrm{Zn}-\mathrm{L}$ bonds (Table 2) increases and the $K_{\mathrm{S}}$ values of complexes raise (Table 1) with the increase of the extraligand basisity. A linear correlation between $\lg K_{\mathrm{S}}$ and $\mathrm{p} K_{\mathrm{BH}^{+}}$values with the regression equation $\lg K_{\mathrm{S}}=0.2564 \cdot \mathrm{p} K_{\mathrm{BH}}++2.4589$ and a correlation coefficient $\mathrm{r}=0.963$, is observed for the

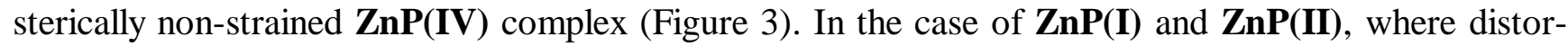
tions of the porphyrin macrocycle are observed, at extracoordination, the function of $\lg K_{\mathrm{S}}$ from $\mathrm{p} K_{\mathrm{BH}}+$ became non-linear and is described by equations:

$$
\begin{aligned}
& \text { for }(\mathbf{L}) \mathbf{Z n P}(\mathbf{I}) \lg K_{\mathrm{s}}=-0.038 \mathrm{p}{K_{\mathrm{BH}^{+}}}^{2}+0.558 \cdot \mathrm{p} K_{\mathrm{BH}^{+}}+1.741 ;(\mathrm{r}=0.984), \\
& \text { for }(\mathbf{L}) \mathbf{Z n P}(\mathbf{I I}) \lg K_{\mathrm{s}}=-0.069 \cdot \mathrm{p} K_{\mathrm{BH}^{+}}^{2}+0.936 \cdot \mathrm{p} K_{\mathrm{BH}^{+}}+0.536 ;(\mathrm{r}=0.979) \text {. }
\end{aligned}
$$

\begin{tabular}{|c|c|c|c|c|c|c|c|c|c|}
\hline Complex & $\begin{array}{c}\mathrm{Zn}-\mathrm{N} 1 \\
\AA \\
\AA\end{array}$ & $\begin{array}{c}\mathrm{Zn}-\mathrm{N} 2 \\
\AA \\
\AA\end{array}$ & $\begin{array}{c}\mathrm{Zn}-\mathrm{N} 3 \\
\AA \\
\AA\end{array}$ & $\begin{array}{c}\mathrm{Zn}-\mathrm{N} 4 \\
\AA \\
\AA\end{array}$ & $\begin{array}{c}\mathrm{Zn}-\mathrm{N}_{\mathrm{L}} \\
\AA \\
\AA\end{array}$ & $\begin{array}{c}\mathrm{Ct}-\mathrm{Zn} \\
\AA \\
\AA\end{array}$ & $\begin{array}{c}\mathrm{N} 1-\mathrm{Ct} \\
\AA \\
\AA\end{array}$ & $\begin{array}{c}\mathrm{N} 3-\mathrm{Ct} \\
\AA \\
\AA\end{array}$ & $\begin{array}{c}\text { N1-N3 } \\
\AA ̊\end{array}$ \\
\hline $\mathrm{ZnP}(\mathrm{I})$ & 2,025 & 2,055 & 2,074 & 2,064 & & 0,049 & 2,024 & 2,073 & 4,097 \\
\hline ZnP(I)+Me-Im & 2,126 & 2,109 & 2,086 & 2,115 & 2,100 & 0,387 & 2,091 & 2,049 & 4,141 \\
\hline $\mathbf{Z n P}(\mathbf{I})+\operatorname{Im}$ & 2,125 & 2,108 & 2,086 & 2,115 & 2,099 & 0,459 & 2,075 & 2,064 & 4,139 \\
\hline $\mathrm{ZnP}(\mathrm{I})+\mathrm{Py}$ & 2,121 & 2,107 & 2,085 & 2,112 & 2,124 & 0,385 & 2,085 & 2,051 & 4,137 \\
\hline $\mathbf{Z n P}(\mathbf{I})+\mathrm{DMP}$ & 2,088 & 2,087 & 2,103 & 2,101 & 2,100 & 0,408 & 2,048 & 2,063 & 4,111 \\
\hline $\mathbf{Z n P}(\mathbf{I})+\mathrm{DMF}$ & 2,069 & 2,058 & 2,021 & 2,049 & 6,871 & 0,097 & 2,066 & 2,018 & 4,085 \\
\hline ZnP(III) & 2.019 & 2.383 & 2.019 & 2.376 & & 0 & 0 & 0 & 4.038 \\
\hline $\mathbf{Z n P}(\mathbf{I I I})+\mathrm{Me}-\mathrm{Im}$ & 2.035 & 2.538 & 2.037 & 2.474 & 1.980 & 0.855 & 1.847 & 1.849 & 3.696 \\
\hline ZnP(III)+Im & 2.032 & 2.522 & 2.033 & 2.484 & 1.978 & 0.834 & 1.853 & 1.854 & 3.707 \\
\hline ZnP(III)+Py & 2.033 & 2.519 & 2.034 & 2.486 & 1.990 & 0.839 & 1.851 & 1.853 & 3.705 \\
\hline $\mathbf{Z n P}(\mathbf{I I I})+\mathrm{DMF}$ & 2.030 & 2.497 & 2.029 & 2.498 & 2.016 & 0.825 & 1.855 & 1.855 & 3.709 \\
\hline ZnP(IV) & 2,055 & 2,043 & 2,011 & 2,043 & & 0,002 & 2,055 & 2,011 & 4,066 \\
\hline ZnP(IV)+Me-Im & 2,070 & 2,101 & 2,105 & 2,096 & 2,095 & 0,408 & 2,029 & 2,065 & 4,094 \\
\hline $\mathbf{Z n P}(\mathbf{I V})+\operatorname{Im}$ & 2,101 & 2,105 & 2,096 & 2,069 & 2,096 & 0,404 & 2,062 & 2,056 & 4,118 \\
\hline ZnP(IV)+Py & 2,069 & 2,095 & 2,101 & 2,100 & 2,119 & 0,400 & 2,031 & 2,062 & 4,093 \\
\hline ZnP(IV)+DMP & 2,085 & 2,104 & 2,095 & 2,053 & 2,203 & 0,429 & 2,040 & 2,051 & 4,091 \\
\hline $\mathbf{Z n P}(\mathbf{I V})+\mathrm{DMF}$ & 2,055 & 2,043 & 2,011 & 2,042 & 7,324 & 0,006 & 2,055 & 2,011 & 4,066 \\
\hline $\mathrm{ZnP}(\mathrm{IV})+$ & 2,011 & 2,045 & 2,055 & 2,040 & 7,919 & 0 & 2,011 & 2,055 & 4,066 \\
\hline $2 \mathrm{DMF}$ & & & & & 7,621 & & & & \\
\hline
\end{tabular}

Table 2. Some geometric characteristics of pentacoordinated Zn-porphyrins. 

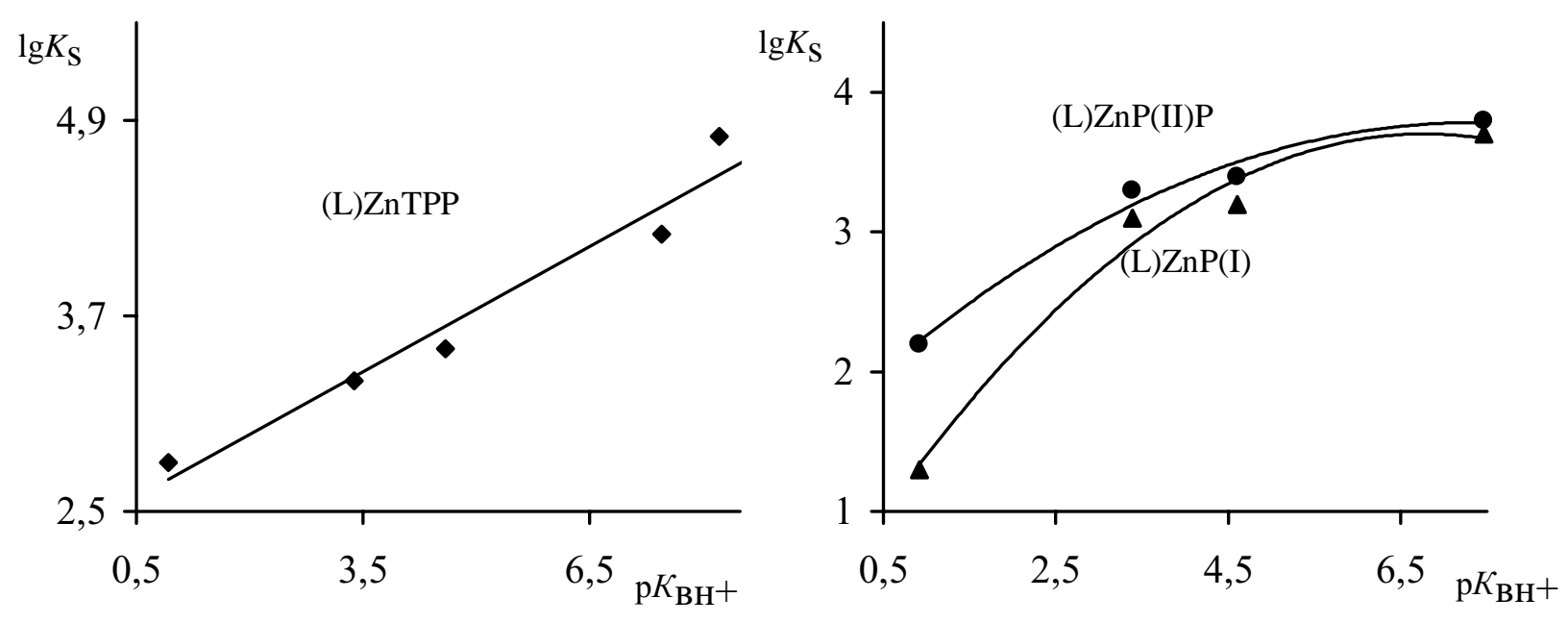

Figure 3. Dependency of extracomplex stabilities of Zn-porphyrins on the basisity of added extraligands.

On the basis of quantum - chemical calculations for N-containing extraligand structures the linear correlation between their basisity and the energy of protonation $E_{\mathrm{p}}$ (Figure 4 ) is obtained.

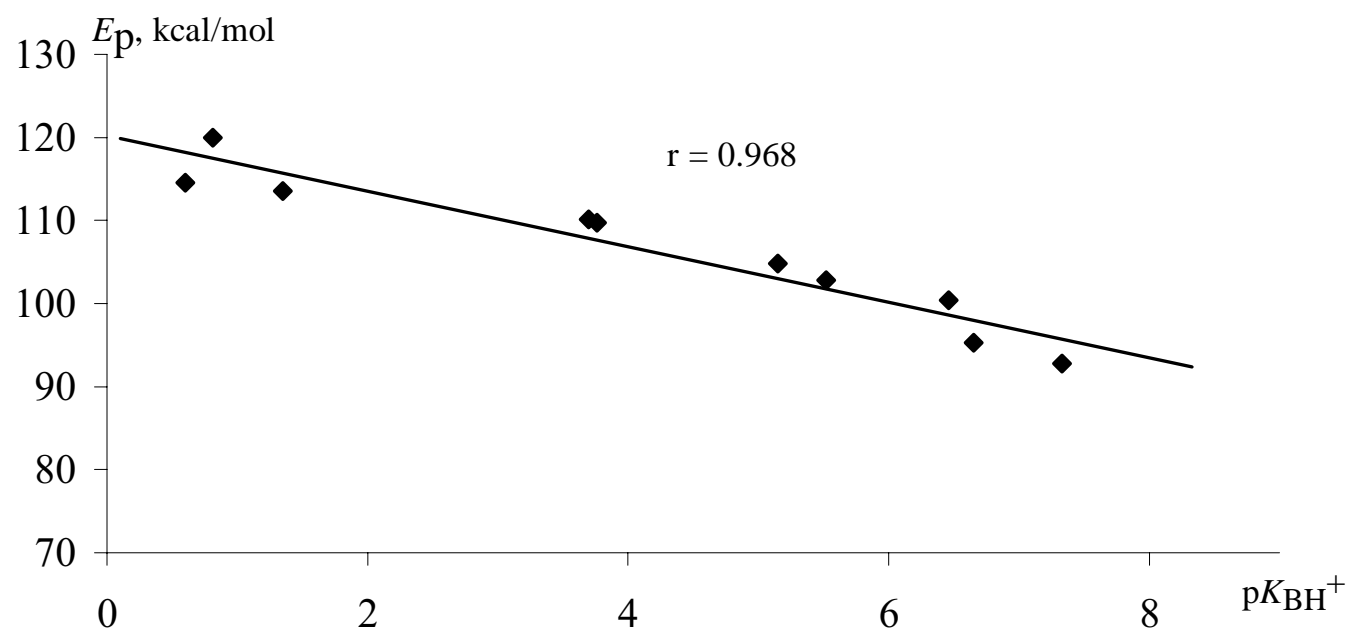

Figure 4. The dependence of protonation energy of nitrogen-containing molecules on their basisity.

Calculated $\mathrm{p} K_{\mathrm{BH}}+$ values compared with data from literature [14] in most cases is notedto be not more than $10 \%$ higher than values of $\mathrm{p} K_{\mathrm{BH}^{+}}$(calcul) and $\mathrm{p} K_{\mathrm{BH}^{+}}{ }^{*}$ (Table 3, Figure 5). In our opinion it allows us to use calculated energy of protonation for the evaluation of the basisity of nitrogen-containing compounds. 
Table 3. Calculated values of protonation energy and basisity of nitrogen-containing molecules.

\begin{tabular}{|l|c|c|c|}
\hline \multicolumn{1}{|c|}{ Extraligand } & $\mathrm{p} K_{\mathrm{BH}^{+}}{ }^{*}$ & $\mathrm{p} K_{\mathrm{BH}^{+}(\mathrm{calc} .)}$ & $E_{\mathrm{p}}, \mathrm{kcal} / \mathrm{mol}$ \\
\hline Me-Im & 7.33 & 8.22 & 92.73 \\
Im & 6.65 & 7.46 & 95.27 \\
Py & 5.29 & 4.60 & 104.8 \\
3,4-dimethylpyridine & 6.46 & 5.93 & 100.38 \\
3-methylpyridine & 5.52 & 5.21 & 102.79 \\
2-formylpyridine & 3.76 & 3.13 & 109.74 \\
3- formylpyridine & 3.7 & 3.01 & 110.14 \\
3-cyanopyridine & 1.35 & 1.99 & 113.56 \\
2-nitropyridine & 0.81 & 0.73 & 119.96 \\
pyrazine & 0.6 & 0.8 & 114.55 \\
DMP & 4.27 & 3.99 & 108.85 \\
DMF & - & 0.92 & 123.3 \\
\hline
\end{tabular}

* Basisity values were obtained by potentiometry in water at $298 \mathrm{~K}$ [14].

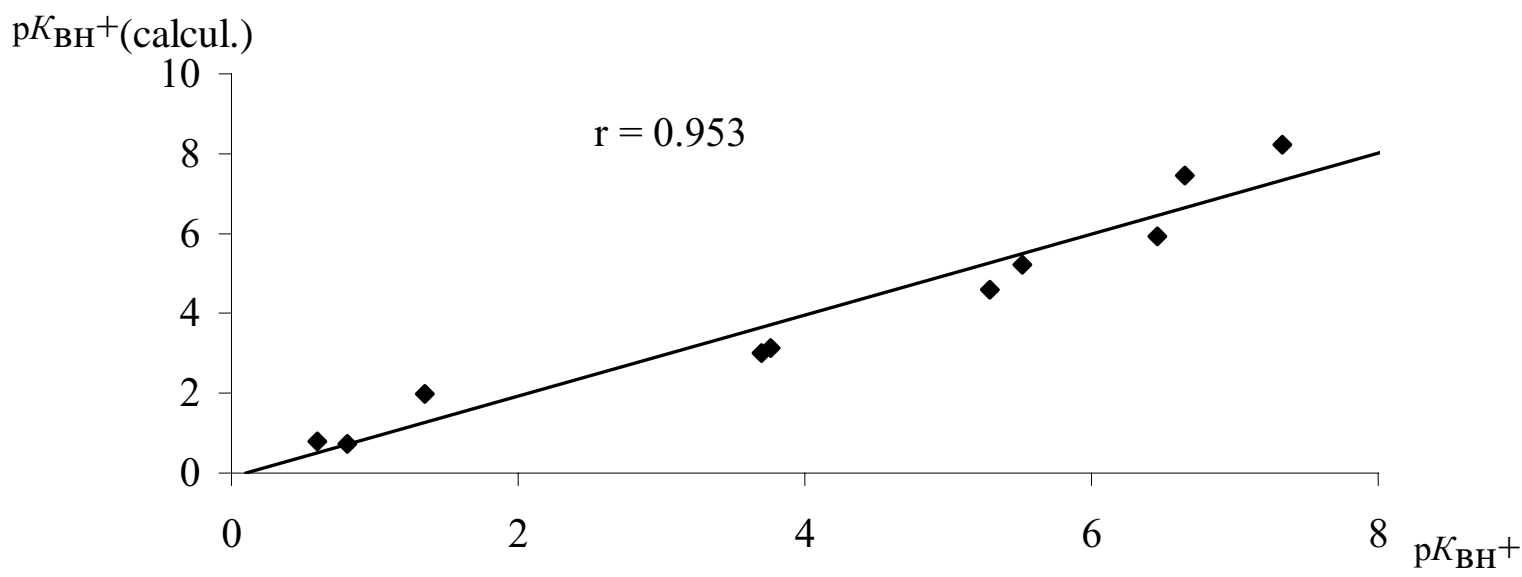

Figure 5. Correlation between calculated and experimental values.

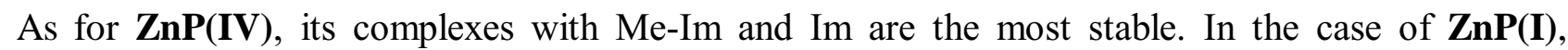
ZnP(II), ZnP(III), interactions with Me-Im are hindered despite of its high basic properties, probably, because of spatial hindrance and distortion of the porphyrin macrocycle .

With the increase of $K_{\mathrm{S}}$ extracomplex values the magnitude of the shift of basic absorption bands $\Delta \lambda$ (Table. 1) increases. The linear dependence with the regression equation $\lg K_{\mathrm{S}}=0.306 \cdot \Delta \lambda+0.039, \mathrm{r}=$ 0.971 is characteristic only for $\mathbf{Z n P ( I V )}$ (Figure 6). Stabilities of (L)ZnP(I), (L)ZnP(II), (L)ZnP(III) extracomplexes varies non-linearly against $\Delta \lambda$, values, and that, in turn, confirms our suppositions about steric stresses taking place in these compounds during extracoordination. Correlations obtained (Figure 
6), in this case, are described by equations:

$$
\begin{aligned}
& \text { for } \mathbf{Z n P}(\mathbf{I}) \lg K_{\mathrm{s}}=-0.006 \cdot \Delta \lambda^{2}+0.2384 \Delta \lambda+1.497, \mathrm{r}=0.952 \\
& \text { for } \mathbf{Z n P}(\mathbf{I I}) \lg K_{\mathrm{s}}=-0.020 \cdot \Delta \lambda^{2}+0.511 \cdot \Delta \lambda+0.299, \mathrm{r}=0.932 \\
& \text { for } \mathbf{Z n P}(\mathbf{I I I}) \lg K_{\mathrm{s}}=-0.069 \cdot \Delta \lambda^{2}+0.917 \cdot \Delta \lambda+0.055, \mathrm{r}=0.979
\end{aligned}
$$
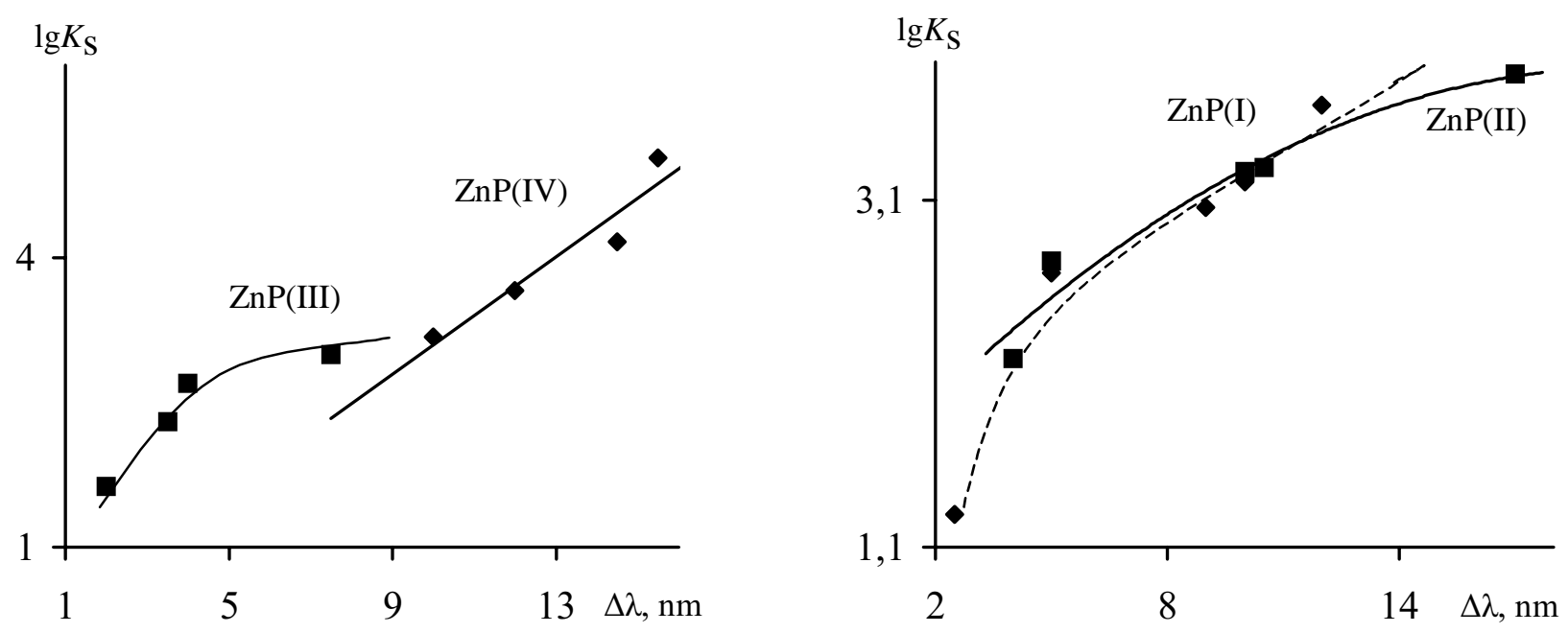

Figure 6. Dependencies of $\lg K \mathrm{~s}$ of $\mathrm{Zn}$-porphyrin extracomplexes and shift values of the basic absorption bands in EAS.

The value of bathochromic shift $\Delta \lambda$, may be used for qualitative characteristic of $\mathrm{Zn}-\mathrm{L}$ bond strength, and consequently, also of value of metal atom exit from the coordination center plane. The use of quantum - chemical methods for calculations of Zn-porphyrins structures, allows us to explain the reasons of modification in stabilities of their extracomplexes as the function of the porphyrin and extraligand natures. Characteristics calculated show that the energy of $\mathrm{Zn}-\mathrm{L}$ bonding formation $\left(E_{\mathrm{b}}\right)$ of extracomplex varies non-linearly with its stability (Table 1 ). The increase of $E_{\mathbf{b}}$ in the series $(\mathbf{L}) \mathbf{Z n P}(\mathbf{I})$ to (L)ZnP(IV) shows the increase in their stabilities.

Zn-porphyrin extracomplexes have square-pyramidal coordination structures with the metal atom emerging slightly from the $\mathrm{N}_{4}$ plane towards the extraligand (Figure 7). On the basis the data in Table 2 the correlations between an exit of metal from a plane of macrocycle and length of $\mathrm{Zn}$ - $\mathrm{L}$ bonding are obtained. We found out that in series of nitrogen-containing bases Im > DMP > Py > DMF the length of $\mathrm{Zn}-\mathrm{Ct}$ in extracomplexes decreases, the stability of $\mathrm{Zn}-\mathrm{N}$ bonding increases at coordination center (Table 2), the interaction of zinc atom with nitrogen atom of extraligand weakens and as the consequence, the overall stability of the metalloporphyrin is reduced (Table 1). Thus the cis-effect of ligands within the structure of Zn-porphyrin extracomplexes is shown to be strong. Finally, it is necessary to point out that some dependence is observed between distortion of a macrocycle ( i.e. the size of a coordination 
cavity) and length of $\mathrm{Zn}-\mathrm{L}$ bonding. The increase of $\mathrm{Zn}-\mathrm{L}$ bonding strength causes the increase of steric stresses in the metalloporphyrin (Table 2).

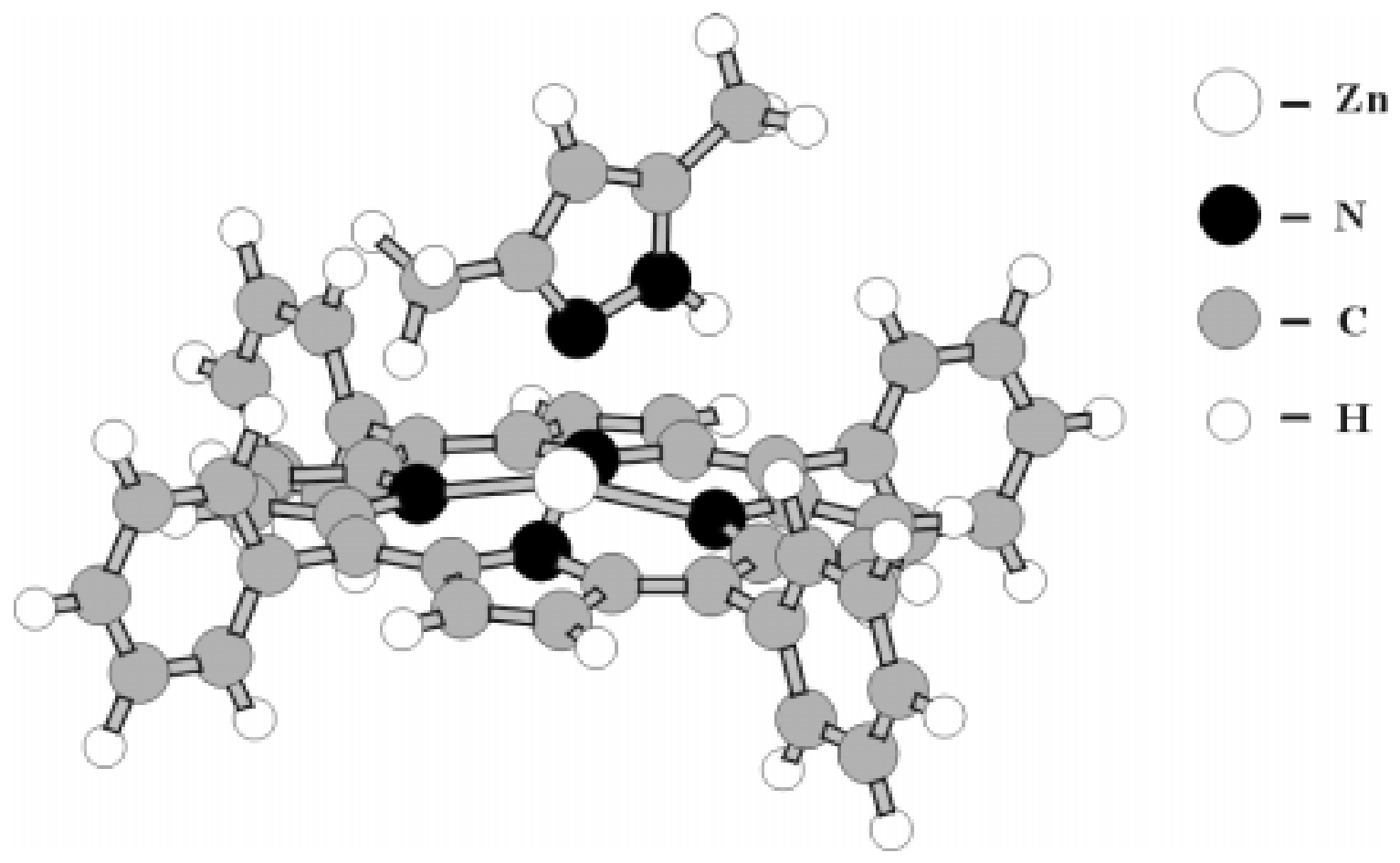

Figure 7. The structure of ZnP(IV) extracomplex with DMF, calculated by the PM3 quantum-chemical method.

\section{Conclusions}

On the basis of experimental and calculated data the dependence between the stability of extracomplexes $\mathrm{Zn}(\mathrm{L}) \mathrm{P}$ and the nature of porphyrin and the basicity of additional molecular ligands was obtained. Correlations between $K_{\mathrm{S}}$ values, the magnitude of basic absorption band displacements $\Delta \lambda$ in EAS of metalloporphyrins and calculated bonding energy of zinc atom with nitrogen atom of extraligand $\left(E_{\mathrm{b}}\right)$ were found.

\section{Experimental}

Zinc complexes with various porphyrin structures (ZnP(I), ZnP(II), ZnP(III), ZnP(IV)) were investigated to systematically study regularities of extracoordination reactions at metalloporphyrins. $\mathrm{ZnP}(\mathbf{I V})$ was taken as model compound. The reaction $\mathrm{ZnP}+\mathrm{Ln}=\mathrm{Zn}(\mathrm{L})_{\mathrm{n}} \mathrm{P}$ was studied at three temperatures: 298K, 303K and 308K (for ZnP (IV): 298K, 308K and 318K) in $o$-xylene, which was chosen because it forms no strong solvate complexes with metalloporphyrins and it is a neutral solvent. Spectrophotometrical titration [1] and computer simulation [2-4] was used to investigate extra-coordination. 
Porphyrins $\quad$ studied $\quad\left(\mathrm{H}_{2} \mathrm{TPP}, \quad 5,15\right.$-(para-butyloxyphenyl)-2,8,12,18-tetramethyl-3,7,13,17tetraethylporphyrin and 5,15-(para-butyloxyphenyl)-2,8,12,18-tetramethyl-3,7,13,17-tetrabutylporphyrin) were synthesized by known methods [5-8].

\section{Zn-tetraphenylporphyrin}

It was synthesized by boiling tetraphenylporphyrin with a tenfold excess of zinc acetate in benzene during 40-50 min. The zinc complex was purified by chromatography on $\mathrm{Al}_{2} \mathrm{O}_{3}$ (activity II) using chloroform as eluent, followed by recrystallization from chloroform. EAS (benzene) $\lambda_{\max } \mathrm{nm}$, (lge): 590.0 (3.49), 550.0 (4.23), 422.5 (5.57).

\section{Zn-5,15-(para-butoxyphenyl)-2,8,12,18-tetramethyl-3,7,13,17-tetraethylporphyrin}

It was obtained in the same way. EAS (benzene) $\lambda_{\max } \mathrm{nm}$, (lge):570.0 (3.98), 534.0 (4.31), 407.0 (5.18).

\section{Zn-5,15-(para-butoxyphenyl)-2,8,12,18-tetramethyl-3,7,13,17-tetrabutylporphyrin}

It was obtained in the same way. EAS (benzene) $\lambda_{\max } \mathrm{nm},(\lg \varepsilon): 575.0$ (3.99), 541.0 (4.25), 412.3 (5.08).

\section{Superimposed Zn-porphyrin}

It was obtained in the same way. EAS ( $o$ - xylene) $\lambda_{\max } \mathrm{nm},(\lg \varepsilon): 587.0(4.22), 549.0(4.43), 410.0$ (5.34).

Changes in metalloporphyrin EAS with the concentration of extraligand allowed us to use a spectral method for study of extracoordination. The experimental technique and calculations of stability constants of extracomplexes $\left(K_{\mathrm{S}}\right)$ are discussed in more detail in the literature [1, 9-12]. The quantum chemical calculations were carried out by a combination of conjugated gradient methods [13]. The condition of termination of the optimization was given by a gradient of $0.04 \mathrm{~kJ} / \mathrm{mol}$.

\section{References and Notes}

1. Bulatov, M. I.; Kalinkin I. P. Praktitcheskoe rukovodstvo po fotokolometritcheskim i spektrofotometritcheskim metodam analiza. Khimia: Leningrad, 1968; p 183.

2. Stewart, J.J.P. J. Comput. Chem. 1989, 10, 209 - 220.

3. Stewart, J. J. P. J. Comput. Chem. 1989, 10, 221 - 229.

4. Stewart, J. J. P. J. Computer - Aided Molecular Design. 1990, 4, 1 - 105.

5. Treibs, A. J. Ann. Chem. 1967, 718, 183. 
6. Treibs, A.; Haberle, N. Ann. Chem. 1968, 719, 183.

7. Mamardashvili, N.Zh.; Semeykin, A.S.; Golybchikov, O.A. Rus. J. Org. Chem. 1993, 29, 1213.

8. Mamardashvili, N.G.; Semeykin, A.S.; Berezin, B.D.; Golybchikov, O.A. Sposob poluchenia 5,15diphenylporphyrinov. A. S. USSR, №1671665, 22 Apr. 1991.

9. Karmanova, T. V.; Koyfman, O. I; Berezin, B. D. Rus. J. Coord. Chem. 1983, 9, 772 - 776.

10. Koroleva, T. A.; Koyfman, O. I; Berezin B. D. Rus. J. Coord. Chem. 1983, 7, 2007 - 2012.

11. Karmanova, T. V. Avtoreferat diss. kand. khim. nauk. Ivanovo, 1985, 16.

12. Tipugina, M. J.; Lomova, T. N.; Ageeva, T. A. Rus. J. Org. Chem. 1999, 69, 459 - 463.

13. Fletcher, R. Methods of Optimization. John Wiley \& Sons: New York, 1980; pp 45 - 62.

14. Tablitsi konstant skorostey $i$ ravnovesiy gomolititceskich organicheskich reaktsiy. Izd. VINITI: Moscow, 1976; p 2.

Samples Availability: Available from the authors.

(C) 2000 by MDPI (http://www.mdpi.org). Reproduction is permitted for noncommercial purposes. 